DOI: https://doi.org/10.24164/prosiding.v3i1.16

\title{
"KUE" DARI SITUS GUNUNG SUSURU SEBAGAI JEJAK TEKNOLOGI MASA BERCOCOK TANAM
}

“Kue” from Susuru Mountain Site as a Trace Technology in the Farming Period

\author{
Endang Widyastuti, Nanang Saptono, Rusyanti \\ Balai Arkeologi Jawa Barat \\ Jalan Raya Cinunuk Km.17 Cileunyi, Bandung \\ E-mail: endangwidyastuti6@gmail.com
}

\begin{abstract}
Austronesian culture is a culture that is supported by a group of people initially settling in a particular region who then travel to various other regions in a very wide range of areas. In the Indonesian Archipelago contact with the Austronesian culture had occurred during farming. The form of culture in the technological aspects includes pottery technology and bark processing. In a study conducted in Mount Susuru in the Kertabumi region, artifacts made from terracotta with unique shapes and decorations were found. Terracotta is found in a number and variety of shapes and decorations quite a lot. Local people refer to the artifact as "kue". Based on the comparison of forms through literature studies, this paper aims to determine the relationship of the "kue" with pottery technology and bark processing.
\end{abstract}

Keywords: "kue”, Mount Susuru, earthenware, bark processing.

\begin{abstract}
Abstrak
Kebudayaan Austronesia merupakan budaya yang didukung oleh sekelompok orang awalnya menetap di suatu wilayah tertentu yang kemudian melakukan perjalanan ke berbagai wilayah lainnya dalam rentang area yang sangat luas. Di Kepulauan Indonesia kontak dengan budaya austronesia telah terjadi pada masa bercocok tanam. Bentuk budaya tersebut dalam aspek teknologi diantaranya menyangkut teknologi gerabah dan pengolahan kulit kayu. Dalam penelitian yang pernah dilakukan di Gunung Susuru kawasan Kertabumi, ditemukan artefak berbahan terakota dengan bentuk yang unik dan terdapat beragam goresan di permukaannya. Terakota tersebut ditemukan dalam jumlah dan variasi bentuk serta hiasan yang cukup banyak. Masyarakat setempat menyebut artefak tersebut sebagai "kue". Berdasarkan perbandingan bentuk melalui studi pustaka, tulisan ini bertujuan untuk mengetahui kaitan "kue" tersebut dengan teknologi gerabah dan pengolahan kulit kayu.
\end{abstract}

Kata kunci: "kue”, Gunung Susuru, gerabah, pengolahan kulit kayu.

\section{PENDAHULUAN}

$\mathrm{K}$ emampuan membuat gerabah merupakan salah satu lompatan yang besar pada budaya manusia. Kemampuan membuat gerabah mulai muncul pada masa bercocok tanam. Berbicara mengenai kemampuan membuat gerabah tidak dapat dilepaskan dengan keberadaan rumpun bangsa Austronesia. Bangsa Austronesia telah bermigrasi ke seluruh pelosok dunia hingga dapat ditemukan di hampir separo belahan dunia. Mengenai perpindahan Bangsa Austronesia ini beberapa ahli telah memaparkan pendapatnya tentang asal usul dan jalur perpindahannya (Noerwidi, 2014, hal. 2). Dalam bermigrasi mereka 
juga membawa budaya yang kemudian dikembangkan di tempat yang baru (Bellwood, 2000, hal. 299-353). Pada waktu kehidupan mereka sudah menetap, mereka mempunyai banyak waktu luang untuk mengembangkan keahlian-keahlian baru, diantaranya kemampuan membuat barangbarang gerabah dan pengolahan kulit kayu (Simanjuntak, 2015, hal. 32).

Situs Gunung Susuru adalah salah satu situs di kawasan Kertabumi, secara administratif termasuk Dusun Bunder, Desa Kertabumi, Kecamatan Cijeungjing, Kabupaten Ciamis. Di kawasan Kertabumi terdapat beberapa lokasi yang mengandung tinggalan arkeologis, berupa makam, punden, dan gua-gua. Pada survei yang dilakukan di kawasan Gunung Susuru banyak ditemukan benda-benda tembikar/ gerabah yang berbentuk pipih panjang. Pada sisi-sisinya terdapat goresan dengan bentuk yang berbeda-beda. Oleh penduduk setempat benda tersebut biasa dinamakan "kue" (Widyastuti, 2001, hal. 101).

Permasalahan yang diangkat dalam tulisan ini adalah apa fungsi gerabah yang disebut "kue" tersebut? Pembahasan mengenai artefak ini pernah penulis lakukan pada artikel terdahulu. Dalam artikel tersebut baru dijabarkan mengenai bentuk dan motif-motif goresan pada benda tersebut (Widyastuti, 2001, hal.99-112). Pembahasan mengenai fungsi belum pernah dilakukan. Penyelesaian masalah dilakukan dengan mengidentifikasi bentuk dan goresan pada kue, selanjutnya dilihat kemiripan dengan peralatan yang dibandingkan. Setelah itu ditarik kesimpulan.

Penggunaan tembikar atau gerabah dapat dikelompokkan dalam beberapa jenis. Stanley South, membagi gerabahgerabah tersebut dalam beberapa kelompok berdasarkan tipe artefaknya, yaitu kelompok dapur, hiasan, personal, dan aktivitas. Artefak yang termasuk dalam kelompok dapur tidak hanya terbatas pada benda yang menunjukkan kegiatan mengolah makanan di dapur, tetapi lebih luas lagi yaitu meliputi semua kegiatan memperoleh, memasak, mengolah, menyimpan serta menyajikan bahan makanan. Kelompok artefak hiasan merupakan artefak yang berfungsi untuk hiasan baik di dalam maupun di luar rumah misalnya pot, vas, dan arca keramik. Kelompok artefak personal merupakan artefak-artefak yang berfungsi untuk keperluan yang bersifat pribadi, sebagai contoh adalah perhiasan dan perlengkapannya. Sedang kelompok aktivitas adalah artefak yang mencerminkan kegiatan industri, subsistensi, upacara, dan permainan yang berlangsung dalam rumah tangga atau di luar rumah tangga (Rangkuti, 1986, hal. 138-142).

\section{PEMBAHASAN}

Kawasan Kertabumi secara administratif berada di Desa Kertabumi, Kecamatan Cijeungjing, Kabupaten Ciamis, Jawa Barat. Kawasan tersebut merupakan sebuah area yang diapit oleh dua sungai yaitu Ci Leueur dan $\mathrm{Ci}$ Muntur. Kedua sungai tersebut bertemu di sebelah timur laut Gunung Susuru. Gunung Susuru merupakan suatu tonjolan bukit yang terbentuk oleh batuan breksi vulkanik. Ketinggian daerah Gunung Susuru dan sekitarnya kurang lebih $100 \mathrm{~m}$ di atas permukaan laut.

Di kawasan Kertabumi terdapat beberapa tinggalan arkeologi yang tersebar pada beberapa lokasi yaitu di Bojong Gandu, Gunung Susuru, Lulumpang, dan Kompleks Makam Prabudimuntur. Tinggalan arkeologi di lokasi tersebut beranekaragam, dari 
yang bersifat monumental, non-artefaktual, dan artefaktual. Tinggalan arkeologi yang bersifat monumental berupa batu datar, punden berundak, dan gua-gua buatan, bersifat non-artefaktual berupa kerak besi, mineral besi, dan arang, serta artefak berupa keramik dan tembikar (Agus, 2001).

Temuan yang cukup menarik ditemukan terutama di situs Bojong Gandu yaitu berupa fragmen-fragmen tembikar/gerabah. Fragmen tembikar yang ada berasal dari bentuk wadah dan bukan wadah. Tembikar dari bentuk wadah dibuat dengan teknologi sederhana menggunakan roda putar, tatap pelandas, dan gabungan keduanya. Bahan bertekstur sedang sampai kasar, dengan temper berupa pasir, pasir kwarsa, dan sekam. Sebagian besar tembikar merupakan tembikar polos, tetapi beberapa tembikar ada yang berhias pola garis-garis. Hiasan menggunakan teknik tekan. Sedang tembikar dari bentuk bukan wadah berasal dari bentuk tungku, bata, gacuk, dan terakota/kue (Widyastuti, 2002).

Terakota yang disebut kue dari situs Bojong Gandu seluruhnya berjumlah 34 keping. Terakota-terakota tersebut berbentuk pipih panjang dengan bermacam-macam variasi penampang lintang yaitu segi empat, setengah lingkaran, elips, dan trapesium. Goresan yang terdapat pada permukaan terakota tersebut dan penempatannya menunjukkan adanya variasi. Terakota yang berpenampang lintang segi empat seluruhnya berjumlah 12 keping, dari jumlah temuan tersebut yang polos berjumlah 3 keping, yang bergores pada satu sisi berjumlah 2 keping, yang bergores pada dua sisi berjumlah 5 keping, yang bergores pada tiga sisi berjumlah 1 keping, dan yang mempunyai goresan pada lima sisi berjumlah 1 keping. Terakota yang berpenampang lintang setengah lingkaran seluruhnya berjumlah 20 keping. Terakota tersebut yang polos berjumlah 2 keping, goresan pada satu sisi berjumlah 13 keping, dan yang mempunyai goresan pada dua sisi berjumlah 5 keping. Terakota yang berpenampang lintang elips dan trapesium masing-masing berjumlah 1 keping. Terakota-terakota tersebut terdapat goresan pada dua sisinya.

Tabel 1. Kemunculan bentuk goresan pada terakota dari situs Bojong Gandu

\begin{tabular}{clc}
\hline No & \multicolumn{1}{c}{ Bentuk goresan } & Jml. \\
\hline 1 & $\begin{array}{l}\text { garis-garis menyerong } \\
\text { saling berpotongan } \\
\text { garis-garis saling berpo- } \\
\text { tongan tegak lurus }\end{array}$ & 6 \\
3 & $\begin{array}{l}\text { garis-garis miring dipo- } \\
\text { tong garis mendatar }\end{array}$ & 3 \\
4 & garis-garis bergelombang & 4 \\
5 & motif duri ikan & 7 \\
6 & garis-garis miring & 8 \\
7 & garis-garis tegak & 3 \\
8 & garis-garis mendatar & 6 \\
9 & pola anyaman bilik & 4 \\
& bambu & \\
10 & lingkaran & 2 \\
11 & garis-garis bersudut & 1 \\
12 & polos & 5 \\
\hline
\end{tabular}

Sumber: (Widyastuti, 2001) dengan modifikasi.

Mengenai bentuk-bentuk goresannya, dari 34 buah terakota terdapat 5 keping polos, sedangkan terakota yang lain mempunyai goresan-goresan dengan bentuk garis-garis menyerong saling berpotongan, garis-garis saling berpotongan tegak lurus, garis-garis miring dipotong garis mendatar, garis-garis bergelombang, motif duri ikan, garis-garis miring, garis-garis tegak, garisgaris mendatar, pola anyaman bilik bambu, lingkaran, garis-garis bersudut (gambar 1 dan foto 1). Beberapa bentuk goresan 
PROSIDING Q Seminar Nasional Arkeologi 2019: 137-143

tersebut dapat muncul secara bersama-sama dalam satu terakota tetapi dapat pula satu terakota hanya mempunyai satu jenis bentuk goresan (lihat tabel 1).
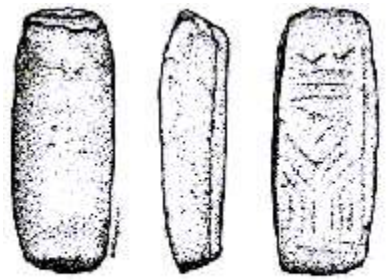

L1. $\mathbf{s}$ 0 $4 \mathrm{~cm}$

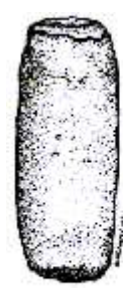

L1. 3
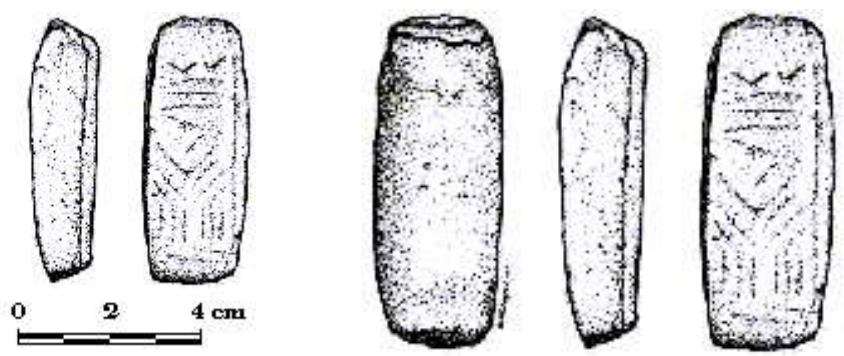

L1. $\mathbf{s}$

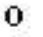

$4 \mathrm{~cm}$
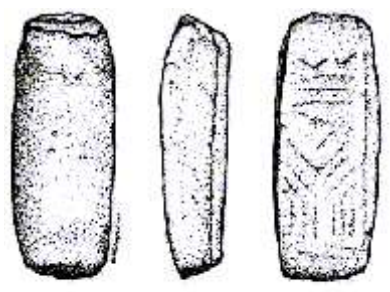

L1. 3
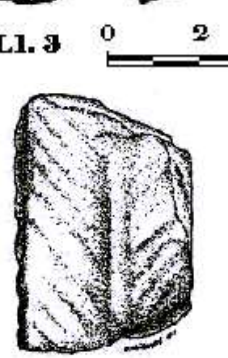

Ed. 3
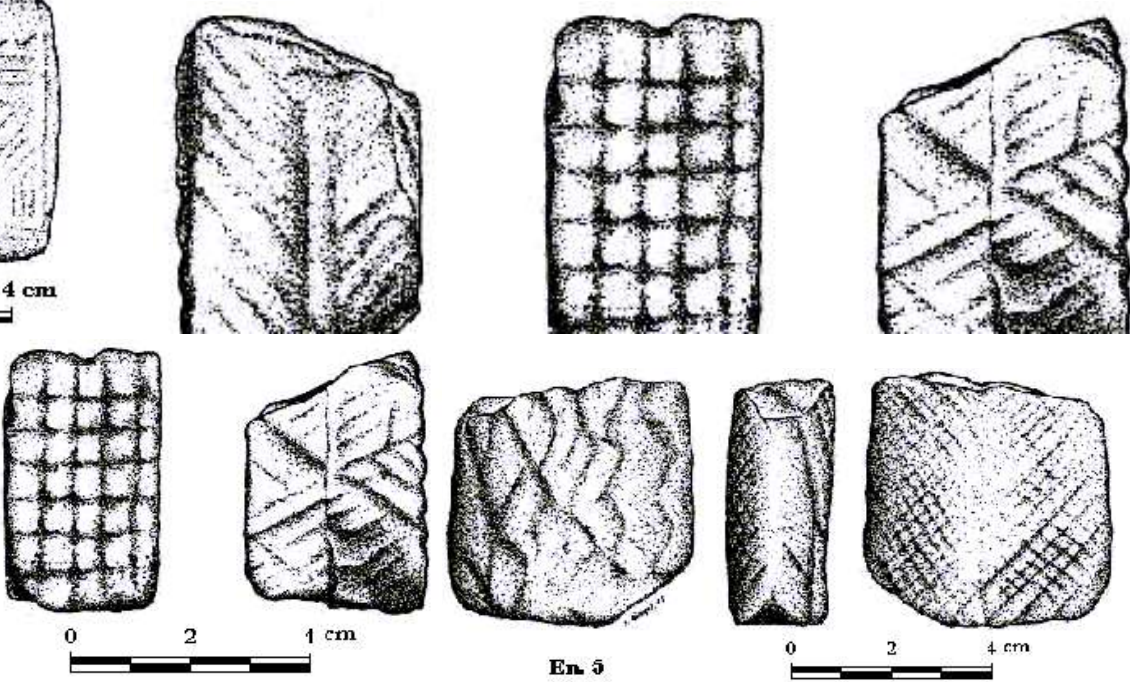

Gambar 1. Bentuk-bentuk goresan yang terdapat pada "kue" (Sumber: Dokumen Balai Arkeologi Bandung, 2002).
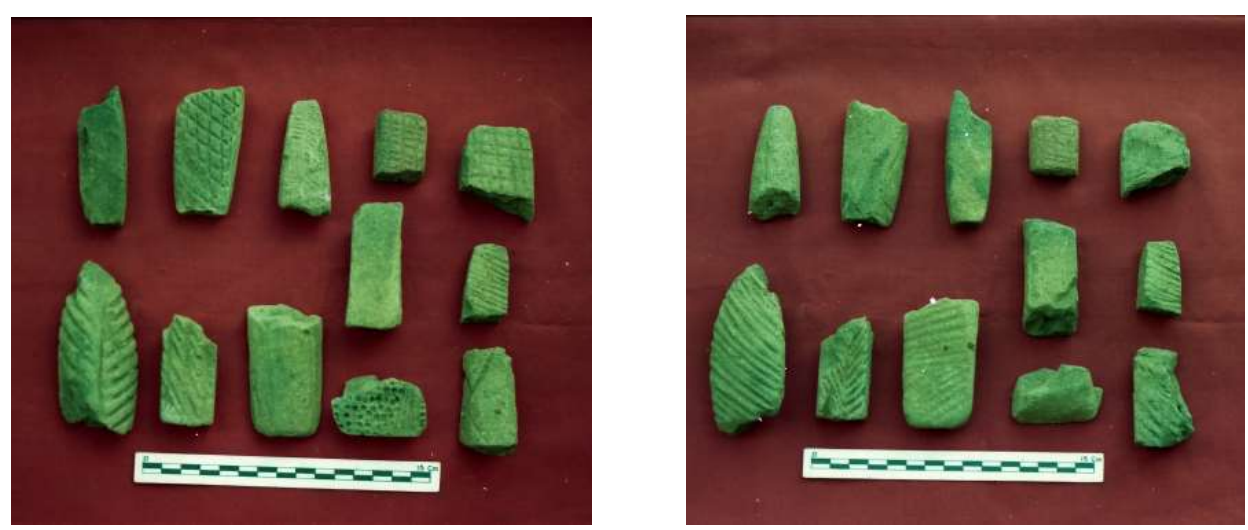

Foto 1. Bentuk-bentuk goresan yang terdapat pada "kue" (Sumber: Dokumen Balai Arkeologi Bandung, 2002). 
Pemakaian gerabah atau tembikar seiring dengan kebutuhan manusia akan wadah untuk persediaan bahan makanan dalam jangka waktu tertentu. Pada masa itu tembikar dibuat dan digunakan hanya untuk menyimpan dan memasak bahan makanan. Tradisi pembuatan tembikar terus berkembang, pada masa pengaruh Hindu-Budha tradisi pembuatan tembikar mengalami perkembangan pesat, baik dalam kualitas maupun keanekaragaman bentuknya. Pada masa itu, mulai dikenal pula tembikar yang bukan wadah. Benda-benda tembikar yang berfungsi sebagai wadah selain yang telah dikenal sebelumnya seperti periuk dan tempayan, juga telah dikenal jenis-jenis lain seperti wadah lampu minyak (clupak). Sedangkan benda-benda tembikar bukan wadah misalnya patung terakota, dinding sumur, batu bata, dan unsur-unsur bangunan lainnya. Selanjutnya pada masa pengaruh Islam, tradisi pembuatan tembikar terus berkembang, terutama dalam hal jenisnya. Perkembangan tradisi pembuatan tembikar tersebut bahkan terus berkembang sampai masa kini (Soegondho, 1995, hal. 5-8).

Proses pembuatan gerabah secara tradisional terdiri dari beberapa langkah utama, diantaranya yaitu penyiapan bahan, proses pembentukan, penggarapan permukaan, pengeringan, dan pembakaran (McKinnon, 1996, hal. 9-22). Dalam proses penyiapan bahan terutama adalah untuk membersihkan bahan tanah liat dari kotorankotoran yang terbawa. Selain itu juga mencampur dengan bahan tambahan yang diperlukan. Selanjutnya mulai dilakukan pembuatan bentuk yang dikehendaki. Proses pembentukan ini dapat dilakukan baik dengan alat maupun tanpa alat. Teknik yang sering digunakan dalam pembentukan ini adalah pijit, spiral, cincin, lempeng, cetak, roda putar dan tatap-pelandas. Setelah selesai tahap pembentukan, kemudian mulai penggarapan permukaan. Proses ini meliputi penghalusan permukaan dan pemberian hiasan. Pada proses ini, selain mempunyai tujuan praktis untuk memperkecil poripori juga mempunyai tujuan estetis yaitu untuk memperindah permukaan benda yang dibuat. Memperindah permukaan benda ini dapat dilakukan dengan berbagai teknik baik menggunakan alat maupun tidak, yaitu teknik tekan, gores, cukil, tempel, lukis, upam dan slip (Wahyudi, 2012, hal. 124-125). Pada penerapan teknik tekan dapat dilakukan tanpa alat yaitu dengan jari, maupun dengan alat yaitu dengan menggunakan alat tatap berhias atau benda yang kecil dan tipis seperti lidi (Wahyudi, 2012, hal. 125). Menilik dari motif-motif hias yang tertera pada terakota "kue" dari Bojong Gandu menunjukkan bahwa motif-motif tersebut lazim tertera pada wadah-wadah gerabah. Sangat memungkinkan bahwa terakota tersebut berfungsi sebagai alat penghias dengan teknik tekan tersebut. Setelah tahap penggarapan permukaan, tahap selanjutnya yaitu pengeringan dan pembakaran, dan gerabah siap untuk digunakan.

Kemampuan lain yang dibawa oleh bangsa Austronesia adalah dalam hal pengolahan kulit kayu menjadi seratserat yang kemudian digunakan menjadi pakaian. Kemampuan membuat bahan pakaian dari kulit kayu telah dimiliki oleh Bangsa Indonesia sejak lama. Temuan alat pemukul kulit kayu yang berasal dari sekitar 3000 tahun yang lalu di situs Kalumpang, Sulawesi menunjukkan bahwa masyarakat Indonesia telah mampu memproduksi sendiri pakaian dengan menggunakan bahan-bahan yang ditemukan di sekitarnya (M. Irfan Mahmud et al., 2019, hal. 88). Bahanbahan untuk membuat serat kulit kayu yang dapat digunakan untuk membuat pakaian 
tercatat ada sembilan jenis diantaranya yaitu kulit kayu pohon beringin/Ara (genus Ficus), daluang (Broussonetia papyrifera), serta cempedak, nangka, sukun (genus Artocarpus). Tanaman-tanaman tersebut dapat ditemui di hutan primer maupun sekunder, baik telah dibudidayakan maupun dapat ditemui secara liar (M. Irfan Mahmud et al., 2019; Rahayu \& Sihotang, 2013; Simanjuntak, 2015).

Pengolahan kulit kayu menjadi bahan pakaian dimulai dengan membersihkan kulit luar dan merendam bahan yang sudah dipilih agar lunak. Selanjutnya bahan yang sudah siap tersebut dipukul-pukul dan dilipat secara berulang-ulang hingga mendapatkan lebar kain yang diinginkan, halus dan tipis (Rahayu \& Sihotang, 2013; Rumagit, 2011; Simanjuntak, 2015). Pemukulan ini dilakukan secara berulang-ulang dengan menggunakan alat pemukul yang disebut "batu ike" atau "popo". Batu Ike atau popo ini terdiri dari enam tingkatan yang memiliki alur-alur pada permukaannya yang semakin halus pada setiap tingkatnya (Rahayu \& Sihotang, 2013, hal. 270). Bentuk batu ike dengan alur-alurnya mempunyai kemiripan dengan bentuk terakota "kue" dari situs Bojong Gandu. Dengan penggunaan yang semakin halus, memungkinkan bahwa "kue" dari situs Bojong Gandu ini merupakan alat yang dipergunakan untuk menghaluskan kulit kayu pada tahap terakhirnya, sehingga diperoleh serat kayu yang siap dipergunakan untuk bahan pakaian.

\section{SIMPULAN}

Migrasi yang dilakukan oleh bangsa Austronesia ribuan tahun yang lalu dilakukan ke berbagai wilayah, termasuk hingga ke Indonesia. Bangsa Austronesia membawa keahlian mereka dalam bermigrasi, dan mengembangkannya lebih lanjut setelah mereka hidup dengan cara menetap dan mempunyai banyak waktu luang.

Diantara kemajuan yang dikembangkan oleh Bangsa Austronesia adalah membuat benda-benda dari tanah liat yang dibakar atau gerabah/tembikar dan pengolahan kulit kayu yang digunakan sebagai bahan pakaian. Berdasarkan bentuknya, terakota "kue" dari Situs Bojong Gandu/Gunung Susuru mempunyai kemiripan dengan alat untuk menghias wadah gerabah maupun alat pemukul kulit kayu.

\section{DAFTAR PUSTAKA}

Agus. (2001). Laporan Hasil Penelitian Arkeologi Penelitian Arkeometri di Kawasan Kertabumi dan Sekitarnya, Kec. Cijeungjing, Kabupaten Ciamis, Jawa Barat. Bandung.

Bellwood, P. (2000). Prasejarah Kepulauan Indo-Malaysia (Edisi Revisi). Jakarta: Gramedia Pustaka Utama.

M. Irfan Mahmud, Hakim, B., Fakhri, M, R. S., Suryatman, \& Saiful, A. M. (2019). Kebudayaan Kalumpang, Sulawesi Barat (3800 BP - 400 AD). (Moh. Hasjmy IbrahimMahmud \& M. Irfan, Ed.). Makassar: Balai Arkeologi Sulawesi Selatan.

McKinnon, E. E. (1996). Buku Panduan Keramik. Jakarta: Pusat Penelitian Arkeologi Nasional.

Noerwidi, S. (2014). Migrasi Austronesia Dan Implikasinya Terhadap Perkembangan Budaya di Kepulauan Indonesia. AMERTA, Jurnal Penelitian dan Pengembangan Arkeologi, 32(1), 1-76.

Rahayu, M., \& Sihotang, V. B. L. (2013). Serat Kulit Kayu Bahan Sandang: Keanekaragaman Jenis Dan Prospeknya Di Indonesia. Berita Biologi, 12(3), 269- 275. 
Rangkuti, N. (1986). Analisis Pola Artefak Situs Permukiman di Caruban, Lasem. In Pertemuan Ilmiah Arkeologi IV, Buku III. Konsepsi dan Metodologi. Jakarta: Pusat Penelitian Arkeologi Nasional.

Rumagit, R. F. (2011). Inventarisasi Kain Tradisional "Kumpe” Kain Kulit Kayu Dalam Kehidupan Masyarakat Sulawesi Tengah. (Y. Y. Sunarya, Ed.). Jakarta: Direktorat Tradisi, Direktorat Jenderal Nilai Budaya, Seni dan Film, Kementerian Kebudayaan dan Pariwisata.

Simanjuntak, T. (2015). Progres Penelitian Austronesia di Nusantara. AMERTA, Jurnal Penelitian dan Pengembangan Arkeologi, 33(1), 1-76.

Soegondho, S. (1995). Tradisi Gerabah di Indonesia, Dari Masa Prasejarah Hingga Masa Kini. Jakarta: Himpunan Keramik Indonesia.

Wahyudi, W. R. (2012). Tembikar Upacara di Candi-Candi Jawa Tengah Abad Ke-8-10. Jakarta: Wedatama Widya Sastra.

Widyastuti, E. (2001). Temuan Terakota dari Situs Bojong Gandu, Kertabumi, Ciamis: Sebuah Telaah Bentuk dan Ragam Hias". In T. D. dan M. A. Fadillah (Ed.), Manusia dan Lingkungan: Keberagaman Budaya Dalam Kajian Arkeologi (hal. 99 112). Bandung: Ikatan Ahli Arkeologi Indonesia.
Widyastuti, E. (2002). Tembikar dan Keramik dari Kawasan Kertabumi. In E. S. Hardiati (Ed.), Tapak-Tapak Budaya (hal. 98-110). Bandung: Ikatan Ahli Arkeologi Indonesia.

\section{HASIL DISKUSI}

\section{Pertanyaan}

\section{Budianto Hakim (Balai Arkeologi Sulawesi Selatan)}

Mengenai temuan hiasan tanah liat (kue), temuan yang sama juga terdapat pada penelitian di Sulawesi, terutama pada situs-situs Austronesia di Kalumpang. Temuannya memiliki panjang $10 \mathrm{~cm}$ dan dihias pada keempat sisinya. Apa fungsi dari hiasan tanah liat tersebut, apakah amulet atau bekal kubur? Sementara pada situs lain yang berkonteks dengan keramik dan benda logam, hiasan tanah liat tersebut diperkirakan berfungsi sebagai amulet, terutama berdasarkan motif hias yang ada di keempat sisinya.

\section{Jawaban}

1. Masih terbuka kemungkinan tersebut, namun di Gunung Susuru/Bojong Gandu "kue" tersebut tidak ditemukan di situs kubur. Terbuka juga kemungkinan bahwa benda tersebut berfungsi sebagai alat tukar. 